04.1

\title{
Генерация импульсно-периодической последовательности наносекундных искровых разрядов в воздушном промежутке между прозрачными гидрогелевыми электродами
}

\author{
(C) А.Е. Дубинов ${ }^{1,2}$, Ю.П. Кожаева ${ }^{1}$ \\ ${ }^{1}$ Российский федеральный ядерный центр - Всероссийский научно-исследовательский институт экспериментальной \\ фризики, Саров, Россия \\ ${ }^{2}$ Саровский фиизико-технический институт, Саров, Россия \\ E-mail: dubinov-ae@yandex.ru
}

Поступило в Редакцию 15 января 2019г.

В окончательной редакции 15 января 2019г.

Принято к публикации 22 января 2019г.

Впервые продемонстрировано применение прозрачных для видимого света гидрогелевых электродов для генерации искровых разрядов с амплитудой тока до $400 \mathrm{~A}$, периодически следующих друг за другом с частотой $250 \mathrm{~Hz}$. Представлены видеоизображения разряда и кратеров, образующихся на поверхности электродов.

DOI: 10.21883/PJTF.2019.08.47614.17704

Искровой разряд представляет собой детально изученный и широко применяемый тип газового разряда [1]. Для его осуществления высоковольтный импульс малой длительности прикладывают к электродам, между которыми находится газ. Чаще всего электродами служат твердотельные металлические катод и анод [2-5]. Часто один или оба электрода в искровых разрядах представляют собой поверхности проводящих жидкостей [6-8].

Иногда для некоторых исследований требуется генерировать искровые разряды на электродах, прозрачных для света видимого диапазона. Такая задача может возникать, например, для удобства визуализации процессов взаимодействия плазмы с электродом.

Металлические электроды непрозрачны. Жидкие электроды (например, в виде водного раствора $\mathrm{NaCl}$ ) могут быть прозрачны, но они текучи под действием силы тяжести и не сохраняют форму так, как металлические электроды.

Известны, например, твердотельные прозрачные электроды, сквозь которые наблюдают за движением плазмы по электроду [9-11]. Такие электроды изготавливаются из стекла с помощью напыления на него тонких проводящих слоев (например, indium-tin-oxide) или из полупроводниковых материалов (например, GaAs: $\mathrm{Cr}$ ). Однако для генерации энергоемких искровых разрядов наносекундной длительности и с большой плотностью тока применение таких электродов затруднительно.

Кроме того, в газоразрядной технике известны также пористые керамические электроды, пропитываемые электролитами $[12,13]$. Они хорошо держат свою форму, но абсолютно непрозрачны.

Обозначим две возможные стратегии поиска прозрачных электродов. Известно, что металлы непрозрачны для света потому, что плазменная частота носителей тока металлах на порядки превышает частоту элек- тромагнитной волны видимого света. Для обеспечения прозрачности следует понизить плазменную частоту для носителей тока в материалах электродов. Это можно сделать двумя путями:

1) уменьшая концентрацию носителей и, следовательно, увеличивая удельное сопротивление (как это обеспечивается в полупроводниках с электронами и дырками в качестве носителей тока);

2) увеличивая массу носителей (как это обеспечивается в водных растворах солей с тяжелыми ионами в качестве носителей тока).

В настоящей работе впервые описаны эксперименты, в которых продемонстрирован импульсно-периодический искровой разряд между электродами, изготовленными из гидрогеля, насыщенного соленой водой. Отметим, что ранее гели использовались в исследованиях разрядов в качестве плазмообразующего изолятоpa $[14,15]$, однако исследований электрических разрядов с гелевым электродами прежде не проводилось.

Как оказалось, гелевые электроды, насыщенные водным раствором соли, надолго сохраняют свою форму, имеют ионную проводимость и остаются прозрачными в процессе работы.

Для электродов были выбраны шарики из полиакриламида (polyacrylamide), известные под торговой маркой „Orbeez“. В сухом состоянии они имеют диаметр $\sim 2.5 \mathrm{~mm}$ и массу $\sim 20 \mathrm{mg}$. Для наполнения шариков готовился водный раствор $\mathrm{NaCl}$ в весовой пропорции $8: 100$. Они помещались в соляной раствор и выдерживались там в течение суток при комнатной температуре. Шарики, насыщенные этим раствором, приобретали диаметр 7.5-8.5 mm и массу 220-320 mg. Оказалось, что гидрогелевые шарики достаточно прозрачны и имеют показатель преломления, близкий к показателю преломления воды. Кроме того, они весьма эластичны. 

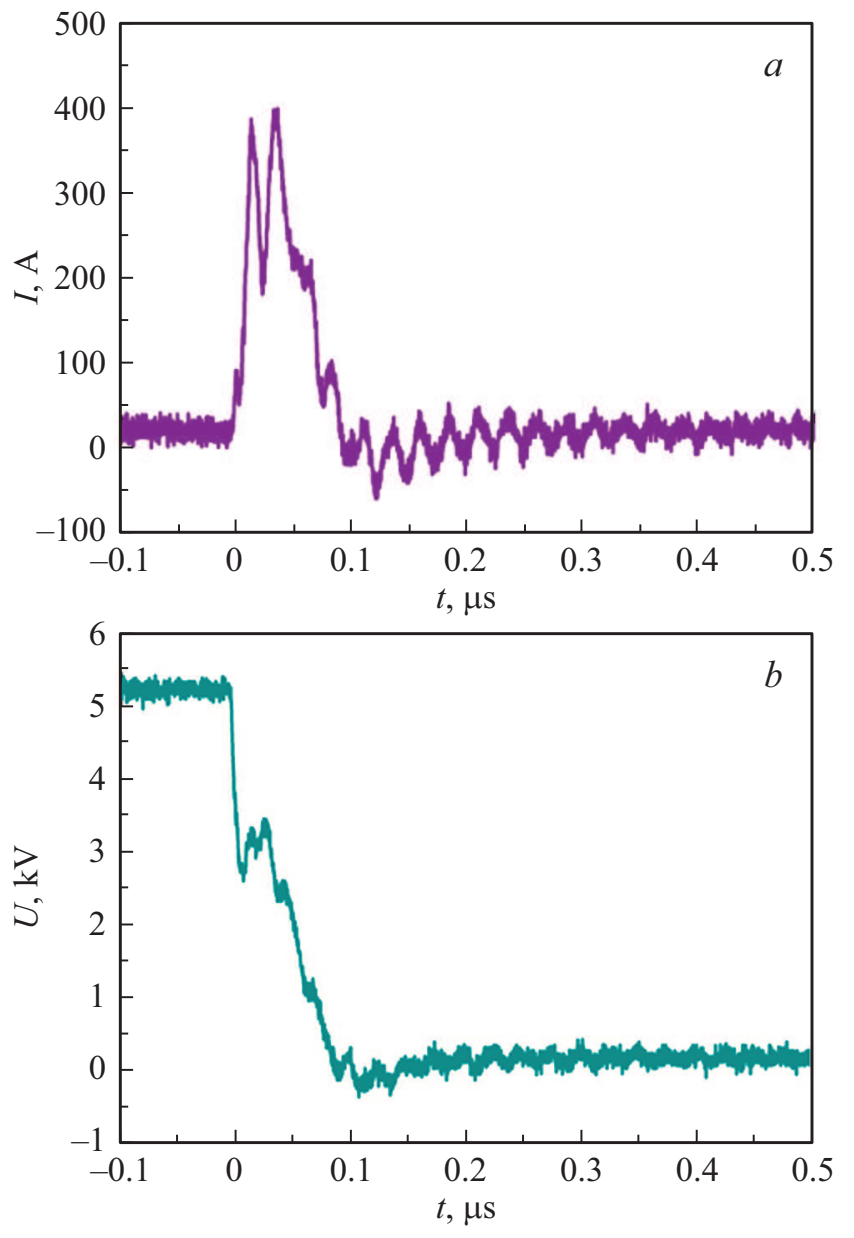

Рис. 1. Синхронизированные осциллограммы тока $(a)$ и напряжения $(b)$ одного из импульсов последовательности.

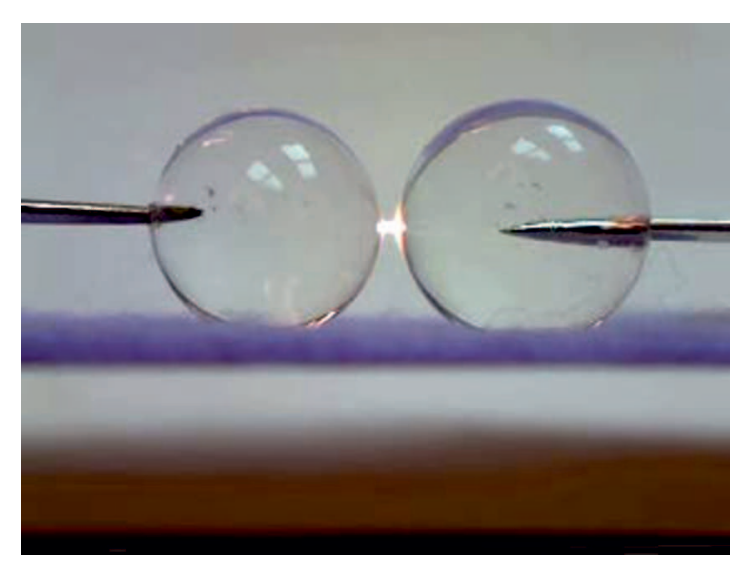

Рис. 2. Изображение искровых разрядов между гидрогелевыми электродами. Слева - катод, справа — анод.

В гидрогелевые шарики вводились игольчатые стальные токовводы на глубину нескольких миллиметров. Расстояние между шариками устанавливалось в диапазоне $2-5 \mathrm{~mm}$.
К токовводам подключался генератор периодической непрерывной последовательности наносекундных высоковольтных импульсов, идущих с частотой $\sim 250 \mathrm{~Hz}$. На рис. 1 показаны синхронизированные осциллограммы тока и напряжения с амплитудами $\sim 400 \mathrm{~A} \mathrm{и} \sim 5 \mathrm{kV}$ соответственно для одного импульса из этой последовательности.

Наблюдение искровых разрядов велось с помощью ручного цифрового микроскопа „Celestron“ (Model 44302-A), позволяющего записывать видео с частотой 20 fps. В итоге мы получали отдельные кадры видеозаписи, на которые накладывались изображения 12 искровых разрядов.

Было показано, что между гидрогелевыми шариками устойчиво возникают искровые разряды. Положение разрядов слегка изменяется от импульса к импульсу. Электроды остаются при этом прозрачными. Изображение искровых разрядов, возникающих между гидрогелевыми электродами, представлено на рис. 2.

После $3 \mathrm{~min}$ непрерывной работы генератора были исследованы участки поверхностей гидрогелевых электродов. Были обнаружены следы образования кратеров, типичные для металлических электродов. Фотографии микрократеров представлены на рис. 3. Эти фотографии свидетельствуют о том, что работа гидрогелевых электродов во многом аналогична работе металлических

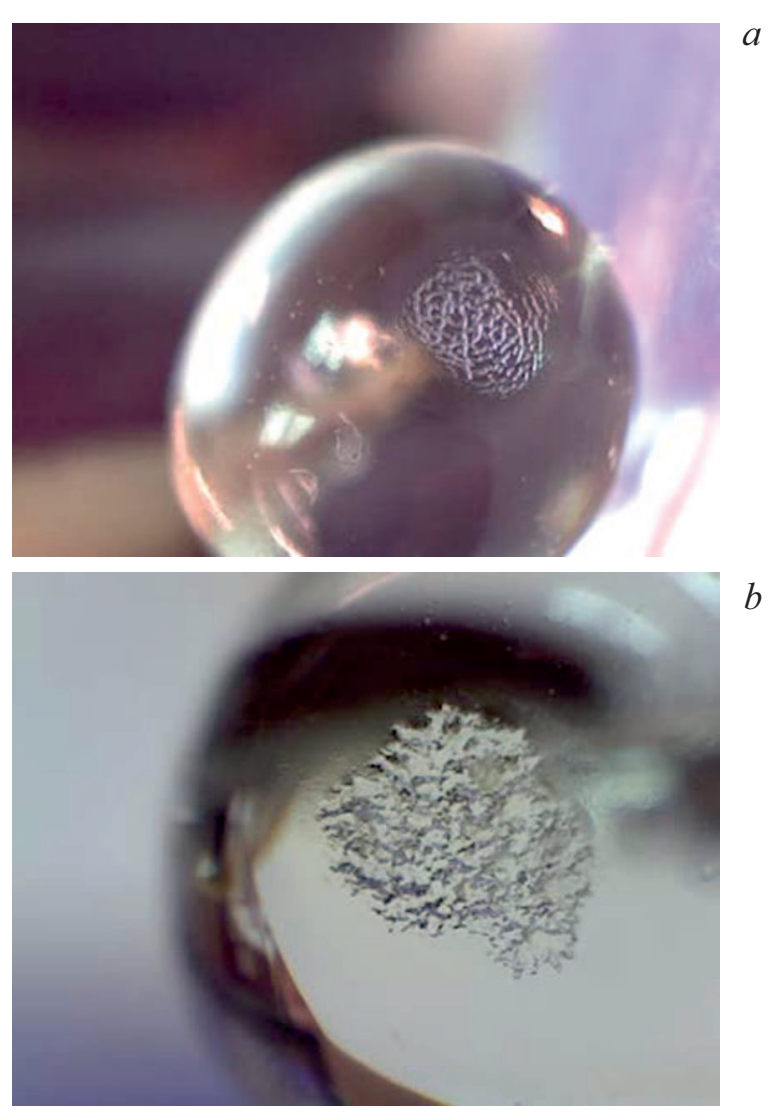

Рис. 3. Изображения кратеров, образовавшихся после $3 \mathrm{~min}$ непрерывной работы. $a-$ катод, $b-$ анод. 
электродов. И при этом гидрогелевые электроды остаются прозрачными для видимого света и сохраняют форму, как твердые тела.

Таким образом, впервые продемонстрировано применение прозрачных для видимого света гидрогелевых электродов для генерации искровых разрядов.

\section{Список литературы}

[1] Базелян Э.М., Райзер Ю.П. Искровой разряд. М.: МФТИ, 1997. $320 \mathrm{c}$

[2] Astanei D., Faubert F., Pellerin S., Hnatiuc B., Wartel M. // Plasma Chem. Plasma Process. 2018. V. 38. N 5. P. 11151132.

[3] Pai D.Z., Lacoste D.A., Laux C.O. // Plasma Sources Sci. Technol. 2010. V. 19. N 6. P. 065015.

[4] Dubinov A.E., Pylayev N.A., Sadovoy S.A., Sadchikov E.A. // IEEE Trans. Plasma Sci. 2014. V. 42. N 10. Pt 1. P. 2648 2649.

[5] Li X., Liu X., Zeng F., Gou X., Zhang Q. // IEEE Trans. Plasma Sci. 2015. V. 43. N 4. Pt 2. P. 1049-1053.

[6] Садриев Р.Ш., Сон Э.Е., Багаутдинова Л.Н., Гайсин Аз.Ф., Гайсин Ф.М. // Теплофизика высоких темпеpaтур. 2017. Т. 55. № 2. С. 317-319.

[7] Дубинов А.Е., Кожсаева Ю.П., Селемир В.Д. // Теплофизика высоких температур. 2018. Т. 56. № 3. С. 469-471.

[8] Dubinov A.E., L'vov I.L., Sadovoy S.A., Senilov L.A., Vyalykh D.V. // IEEE Trans. Plasma Sci. 2013. V. 41. N 2. P. 380-383.

[9] Strümpel C.C., Astrov Yu.A., Purwins H.-G. // Phys. Rev. E. 2000. V. 62. N 4. P. 4889-4897.

[10] Astrov Yu.A., Lodygin A.N., Portsel L.M. // J. Phys. D: Appl. Phys. 2016. V. 49. N 9. P. 095202.

[11] Astrov Yu.A., Lodygin A.N., Portsel L.M., Beregulin E.V. // Phys. Rev. E. 2017. V. 95. N 4. P. 043206.

[12] Гайсин А.Ф., Тазмеев Х.К. // Теплофизика высоких темпеpaтур. 2005. T. 43. № 6. C. 813-819.

[13] Lukes P., Clupek M., Babicky V., Sunka P. // IEEE Trans. Plasma Sci. 2008. V. 36. N 4. Pt 1. P. 1146-1147.

[14] Finis G., Claudi A. // IEEE Dielectr. Electr. Insul. 2008. V. 15. N 2. P. $366-373$.

[15] Leask P.J. // Acta Phys. Pol. A. 2009. V. 115. N 6. P. 998 1000. 